\title{
The treatment of the atrophic clavicular nonunion by double-plate fixation with autogenous cancellous bone graft: a prospective study
}

\author{
Jun Zhang ${ }^{1 \dagger}$, Peng Yin ${ }^{2+}$, Bo Han ${ }^{2}$, Jianmin Zhao ${ }^{1}$ and Bo Yin²*
}

\begin{abstract}
Background: The objective of this study is to assess prospectively the effectiveness of double-plate fixation combined with autogenous cancellous bone graft in the treatment for the atrophic clavicular nonunion.

Methods: Between February 2013 and November 2017, a total of 12 patients with atrophic clavicular nonunion (mean age, $40.4 \pm 9.0$ years, range, 27-60 years) were treated by double-plate fixation with autogenous cancellous bone graft in our institute. The Constant Score System was used to evaluate the preoperative and final outcomes. The Short Form-36 (SF-36) outcome questionnaire was used to assess the final clinical results.

Results: All patients were followed-up, with the average follow-up of $34.7 \pm 6.7$ months (range, 24-48 months). The healing rate was $100 \%$ in our study. The mean time of bony union was 9 weeks (range, $8-10$ weeks). One patient had a postoperative superficial infection, and the patient was cured by oral antibiotics and wound dressing. No implant-related complications (plate-screw loosening or breakage) were observed postoperatively. No vascular injury, neural impairment, or thoracic outlet syndrome was discovered preoperatively or postoperatively. There is a statistical significance between the preoperative and the postoperative constant scores $(P<0.05)$. All the patients were satisfied with their final clinical results by SF-36 outcome questionnaire. Average scores of the physical function and bodily pain components of the SF-36 were $94.2 \pm 7.3$ and $92.5 \pm 5.8$, respectively.

Conclusion: Our results presented that double-plate fixation with autogenous cancellous bone graft is an effective treatment for atrophic clavicular nonunion, especially for those with a significant bone defect.
\end{abstract}

Keywords: Ununited fractures, Clavicle, Internal fixators, Bone transplantation

\footnotetext{
* Correspondence: 2745882307@qq.com

${ }^{\dagger}$ The authors Jun Zhang and Peng Yin are the co-first authors in the study. ${ }^{2}$ Department of Orthopaedics, Beijing Chao-Yang Hospital, China Capital Medical University, Beijing 100020, China

Full list of author information is available at the end of the article
}

(C) The Author(s). 2021 Open Access This article is licensed under a Creative Commons Attribution 4.0 International License, which permits use, sharing, adaptation, distribution and reproduction in any medium or format, as long as you give appropriate credit to the original author(s) and the source, provide a link to the Creative Commons licence, and indicate if changes were made. The images or other third party material in this article are included in the article's Creative Commons licence, unless indicated otherwise in a credit line to the material. If material is not included in the article's Creative Commons licence and your intended use is not permitted by statutory regulation or exceeds the permitted use, you will need to obtain permission directly from the copyright holder. To view a copy of this licence, visit http://creativecommons.org/licenses/by/4.0/. The Creative Commons Public Domain Dedication waiver (http://creativecommons.org/publicdomain/zero/1.0/) applies to the data made available in this article, unless otherwise stated in a credit line to the data. 


\section{Background}

Fractures of the clavicle account for $2.6-10 \%$ of all fractures [1]. Most clavicle fractures could be cured by conservative treatment, except long-term immobilizationcaused various complications, such as pain, deformity, and functional disorder of the shoulder [2]. Therefore, most patients choose surgical treatment to achieve quicker recovery of function and better alignment, especially for the patients with a comminuted clavicle fracture [2, 3]. However, surgery-related complications still exist, and clavicle nonunion is one of the main complications. Olsen BS reported that the rate of clavicle nonunion after conservative treatment was between $0.1 \%$ and $5 \%$ [4], and $2.6 \%$ after surgical treatment [5].

Many surgical techniques have been described for the treatment of clavicle nonunion, including intramedullary fixation with long pins and screws [6], vascularized fibula [7], Ilizarov External Fixator [8], lag screws fixation [9], and bone grafting $[4,10]$; however, there still a different consensus on the best treatment, and every solution has its own set of disadvantages. For instance, the Ilizarov technique has been successfully applied in the treatment for clavicle nonunion, but it always causes pin tract infections and subjective discomfort [8]. Although intramedullary fixation with long pins has partly improved the stability of the nonunion site, many complications still exist, such as migration of the pins and pin breakage. In addition, implantation of the intramedullary pins is difficult because of the irregular anatomic morphology of the clavicle [11-14]. Therefore, more effort is needed to obtain an optimal operative treatment for clavicle nonunion.

The cardinal surgical treatment for a clavicle fracture is one-plate fixation [15]. However, the stability of clavicle nonunion treated with a single plate is unstable in some special cases, especially atrophic nonunion with a bone defect. Therefore, we attempted to use a doubleplate construct (an AO reconstruction plate or a LCDCP plate with auxiliary minor reconstructive plate) to provide a rigid mechanical environment for the treatment of the atrophic clavicular nonunion; in addition, an autogenous cancellous bone was also used for improving the biological environment at the site of nonunion. In this study, we assessed prospectively the effectiveness of the treatment of the atrophic clavicular nonunion by double plate fixation with autogenous cancellous bone graft and aim to provide an alternative surgical method for the disease.

\section{Methods}

We analyzed all patients with clavicle nonunion after operative treatment from February 2013 to November 2017 retrospectively. Our inclusion criteria were adult atrophic clavicular nonunion, and the exclusion criteria were (1) infectious nonunion, (2) pathological nonunion, and (3) nonunion after expectant treatment. According to the inclusion and exclusion criteria, 12 cases were enrolled. Series of laboratory examinations were performed to exclude infection, including C-reactive protein level, white blood cell count, and erythrocyte sedimentation rate. The cutaneous temperature was also measured. A pathological examination of the removed nonunion bone tissue during the revision was carried out to confirm the aseptic bone nonunion. The bone nonunion was defined according to the American Food and Drug Administration (FDA) standard. The nonunion is defined as a fracture that did not heal for 9 months and had no tendency to heal for 3 months $[16,17]$. Before the operation, atrophic sclerosis of the fracture end and sealing of the medullary cavity were identified in X-section. In some patients, we determine nonunion by CT scan (Fig. 1).

In this study, 12 patients with atrophic nonunion were included in the study. Five patients had a right/dominant clavicular nonunion, whereas the remaining seven patients had a left clavicular nonunion. The mean age is $40.4 \pm 9.04$ years (range, $27-60$ years). More details were listed in Table 1.

The patients were placed supine in a beach chair position. The anesthesiologist gave the patient brachial plexus and cervical plexus anesthesia. The longitudinal
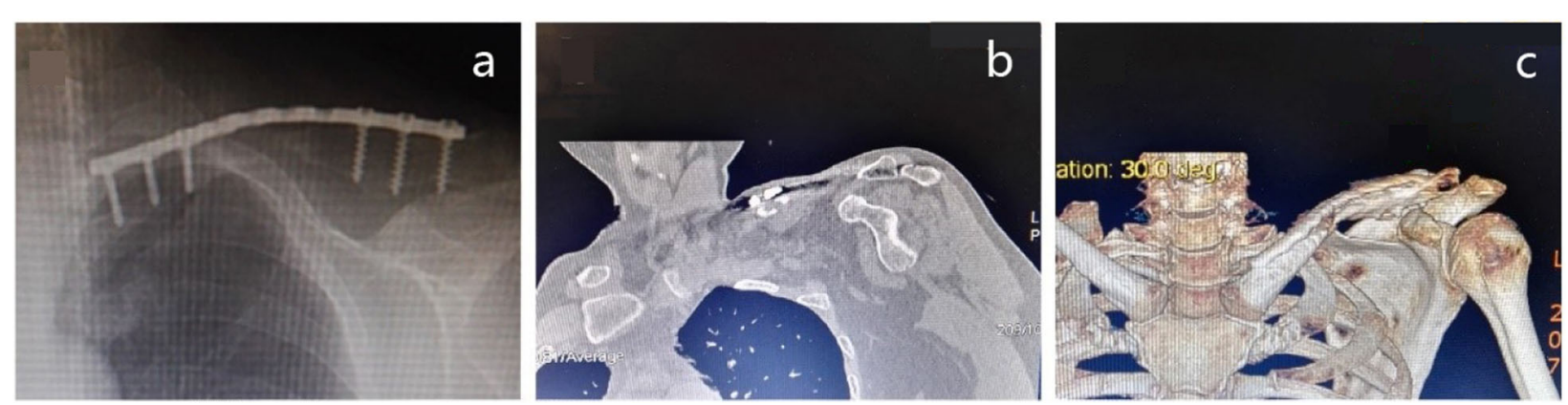

Fig.1 a Clavicle nonunion with plate fixation at 9 months. b Nonunion confirmed by CT scan. c Nonunion was showed in the 3D reconstruction of the clavicle 
Table 1 Demographic characteristics and clinical outcomes of the patients

\begin{tabular}{llllllllll}
\hline Patient no. & $\begin{array}{l}\text { Gender/age } \\
\text { (years) }\end{array}$ & $\begin{array}{l}\text { Non-union } \\
\text { type }\end{array}$ & $\begin{array}{l}\text { Fracture type } \\
\text { AO/OTA } \\
\text { classification }\end{array}$ & $\begin{array}{l}\text { Operative } \\
\text { time } \\
\text { (minutes) }\end{array}$ & $\begin{array}{l}\text { Time to } \\
\text { union } \\
\text { (weeks) }\end{array}$ & $\begin{array}{l}\text { Complication } \\
\text { (mollow-up }\end{array}$ & $\begin{array}{l}\text { Preoperative } \\
\text { constant score }\end{array}$ & $\begin{array}{l}\text { Final outcome } \\
\text { constant score }\end{array}$ \\
\hline 1 & M/37 & Atrophic & B3 & 95 & 9 & None & 48 & 22 & 79 \\
2 & M/39 & Atrophic & B2 & 90 & 9 & None & 42 & 26 & 88 \\
3 & M/60 & Atrophic & B1 & 80 & 10 & infection & 40 & 18 & 70 \\
4 & F/38 & Atrophic & B2 & 105 & 9 & None & 38 & 23 & 80 \\
5 & M/48 & Atrophic & B2 & 85 & 8 & None & 37 & 32 & 82 \\
6 & M/46 & Atrophic & B1 & 100 & 9 & None & 35 & 40 & 89 \\
7 & M/45 & Atrophic & B1 & 95 & 9 & None & 33 & 19 & 78 \\
8 & M/27 & Atrophic & B1 & 90 & 8 & None & 32 & 35 & 88 \\
9 & F/42 & Atrophic & B2 & 85 & 9 & None & 30 & 35 & 82 \\
10 & F/29 & Atrophic & B2 & 90 & 8 & None & 29 & 38 & 80 \\
11 & M/32 & Atrophic & B3 & 90 & 9 & None & 28 & 40 & 85 \\
\hline
\end{tabular}

incision was made along the inferior aspect of the clavicle overlying the nonunion site. After arriving at the nonunion site, sclerotic bones were debrided until the occurrence of the paprika sign (paprika sign is bleeding from the broken ends of the nonunion). It is used to determine the blood flow at the fracture end and assess the viability of the bone fragment) [18], and then, the Kwire was used to drill the medullary cavity. The cardinal plate above the clavicle was usually 9 hole AO locking reconstruction plate or LC-DCP plate $(3.5 \mathrm{~mm}, 6$ screws, double cortex fixation). Plates are contoured to the patient's clavicular anatomy. We used $360^{\circ}$ sufficiently surrounding bone defect site autogenous bone graft technique. The bone autograft material was acquired from the anterior iliac crest. The auxiliary plate in the anterior-posterior plane is usually a 7-9 hole general reconstruction plate or $\mathrm{AO} \mathrm{LCP}(2.7 \mathrm{~mm}, 4$ screws, single cortex fixation). After satisfactory X-ray examination, a large amount of normal saline was used to rinse, a drainage tube was placed, then fascia, subcutaneous tissues, and superficial skin were sutured layer by layer.

Two weeks after surgery, patients were allowed to use the arm out of the sling with the assistance of a physiotherapist. Three weeks later, the patients can resume gentle exercises. Most of the patients were able to elevate the arm for above-shoulder activities at 3 weeks after the operation. Four weeks after surgery, the patients can return to weightlifting and full exercises. The final clinical results were evaluated by the constant score system and Short Form-36 (SF-36) outcome questionnaire $[19,20]$. The constant score could provide a so-called numerical dual assessment: the objective evaluation index including shoulder mobility and muscle strength (65 points) and the subjective evaluation index including pain and functional activity (35 points). It includes the presence of pain (15 points), functional activities (20 points), shoulder mobility (40 points), and muscle strength (25 points) [21]. A score of 100 indicates excellent shoulder function.

The data were analyzed by SPSS 19 software (IBM, Armonk, NY, USA) and the associated IRR package. In this study, the statistical analysis was carried out including the arithmetical mean, standard deviation, and 95\% confidence interval of demographic characteristics and clinical outcomes of the patients. The statistical significance was analyzed for the difference between mean pre- and postoperative constant scores using Student's $t$ test for small, dependent samples.

A value of $P<0.05$ was considered to indicate statistical significance.

\section{Results}

The mean operation time was 85.8 min (range, 80-105 $\mathrm{min}$ ), the mean intraoperative bleeding volume was 220 $\mathrm{ml}$ (range, $150-280 \mathrm{ml}$ ), and the mean hospitalization was 4 days (range, $3-7$ days).

The follow-up for all patients is complete. The average time of follow-up is $34.7 \pm 6.7$ months (range, 24-48 months). The mean time of bone union was 9 weeks (range, 8-10 weeks) (Fig. 2). There was a statistical significance between the preoperative and the postoperative constant scores $(P<0.05)$. The preoperative and postoperative constant scores were shown in Table 1. Average scores noted on the physical function and bodily pain components of the SF-36 were 94.2 (range, 92-99) and 92.5 (range, 90-99), respectively (Fig. 3). The average scores of the constant score and SF-36 outcomes questionnaire on the patients were listed in Table 2.

The healing rate is $100 \%$ in our study. One patient had a postoperative superficial infection, and the patient was 

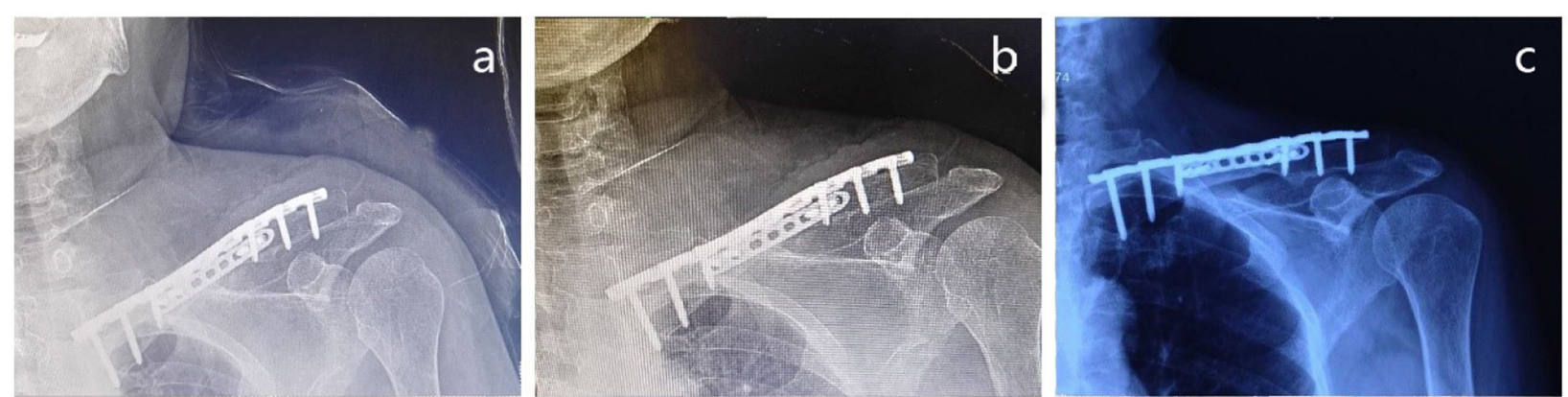

Fig. 2 a 2-Plate revision postoperative immediately. b 2-Plate revision postoperative 3 months. c 2-Plate revision postoperative 1 year

cured by oral antibiotics and wound dressing. No implantrelated complications (plate-screw loosening or breakage) were noted postoperatively. No vascular injury, neural impairment, or thoracic outlet syndrome was observed preoperatively or postoperatively. So far, all patients did not require the removal of the internal fixation.

\section{Discussion}

This is a prospective study about the treatment of the atrophic clavicular nonunion by double-plate fixation with autogenous cancellous bone graft. The present study shows that the operation acquired satisfying outcomes. The healing rate is $100 \%$ in our study. Only one patient had a postoperative superficial infection, which was cured by oral antibiotics and wound dressing. No distinct complications emerged postoperatively.

In our study, the success rate ( $100 \%$ union rate) and mean time of union ( 9 weeks) are comparable with the previous results published by Schnetzke et al. [22], HuiKuang Huang et al. [23], Slavko et al. [8], Kabak et al. [24], Jones et al. [25], and Sadiq et al. [26] (Table 3). Sadiq et al. reported that the incidence of clavicular nonunion was 3\%. Five patients were treated with double plate, and the final healing rate was $100 \%$ [26]. The
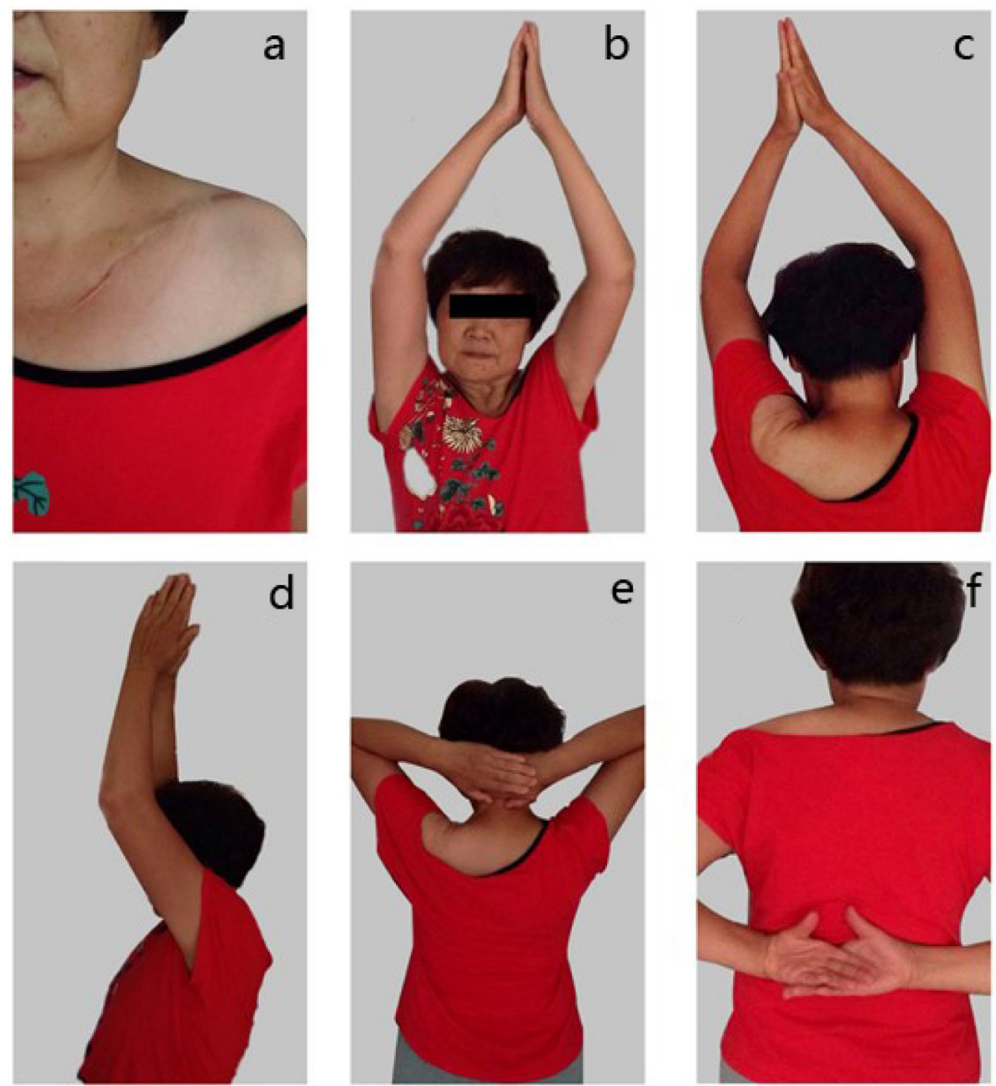

Fig. $\mathbf{3}$ a The appearance of skin incision and shoulder function after operation. b-f Shoulder function after the operation 
Table 2 Average scores of the constant score and SF-36 score system and SF-36 outcomes questionnaire

\begin{tabular}{lllll}
\hline The Constant score & & & SF-36 score \\
\cline { 1 - 2 } \cline { 5 - 6 } Scale & Score & & Scale & Score \\
\hline Pain & $11.0 \pm 2.6$ & & Physical function & $94.2 \pm 7.3$ \\
Functional activities & $17.0 \pm 6.5$ & & Bodily pain & $92.5 \pm 5.8$ \\
Shoulder mobility & $35.2 \pm 1.8$ & & Role-physical & $95.8 \pm 0.8$ \\
Muscle strength & $20.3 \pm 5.3$ & & General health & $91.7 \pm 2.5$ \\
Total score & $77.1 \pm 17.5$ & & Vitality & $96.3 \pm 6.1$ \\
& & Social function & $97.2 \pm 3.7$ \\
& & Role-emotional & $94.1 \pm 2.5$ \\
& & Mental health & $96.5 \pm 4.4$ \\
\hline
\end{tabular}

double-plate fixation technique could achieve a higher healing rate. DPF is more effective to accelerate fracture healing, by providing a more stable mechanical environment in fracture healing. Of course, major fixation stability was realized by locking reconstruction or LC-DCP plate above the clavicle. Firstly, the superior plate could provide the main strength of the structure of double plates. Secondly, the anterior-posterior plate could immobilize bone defects and neutralize the distribution of the part of stress. Moreover, it also could avoid minor displacement of the anterior-posterior plate and strengthen the antirotation stability. The double-plate technique is advantageous in circumferential or atrophic bone loss due to the axial and torsional stable configuration. Furthermore, the bone grafting technique was also a decisive procedure in achieving a satisfactory outcome. We used the $360^{\circ}$ autogenous bone graft technique at the site of bone loss. The bone autograft material was acquired from the anterior iliac crest. It not only can supply biomechanical connections at the defect site, but also rebuild the clavicle blood circulation [22]. Similarly, Haj et al. reported that the treatment of nonunion after limb fracture with or without double plate autograft has achieved satisfactory results [27].

In our experience, double-plate combined with autogenous cancellous bone graft technique is necessary for patients with the atrophic clavicular nonunion, especially for bone defects. An auxiliary small plate in front of the bone defect could increase the fixation stability and maintain the graft position at the nonunion site. Double plates could also allow shoulder girdle early rehabilitation exercise postoperatively due to the absolute stability. In patients with atrophic nonunion, large bone defects often existed after removal of the sclerotic bone, so it is necessary to use an autogenous bone graft to restore clavicle length and double plates to achieve rigid fixation. In addition, there are some other key technology in the surgical procedure: (1) the ends of sclerotic bone should be debrided until the observance of the paprika sign, (2) the medullary cavity should be drilled through the K-wire, and (3) the cardinal plate above the clavicle is usually 9 hole $\mathrm{AO}$ locking reconstruction plate or LC-DCP plate $(3.5 \mathrm{~mm}, 6$ screws, double cortex fixation). (4) Plates should be pre-contoured in terms of the patient's clavicular anatomy. (5) It is essential to handle $360^{\circ}$ autogenous bone graft at a bone defect site. The bone autograft material was acquired from the anterior iliac crest. (6) The auxiliary plate in the anterior-posterior plane is usually 7-9 hole general reconstruction plate or $\mathrm{AO} \mathrm{LCP}(2.7 \mathrm{~mm}, 4$ screws, single cortex fixation). It could improve fixation stability in the anterior-posterior plane of the clavicle.

Data on the demographic characteristics of patients, treatment results, and complication rates were included in our study. However, there are still some limitations to this study. The number of patients was relatively small.

Table 3 Summarization of clavicle nonunion treated by different treatments

\begin{tabular}{|c|c|c|c|c|c|c|c|}
\hline Authors & $\begin{array}{l}\text { Type of } \\
\text { treatment }\end{array}$ & $\begin{array}{l}\text { Mean Age } \\
\text { (year) }\end{array}$ & $\begin{array}{l}\text { Follow-up } \\
\text { (month) }\end{array}$ & $\begin{array}{l}\text { No. of } \\
\text { patients }\end{array}$ & $\begin{array}{l}\text { Type of } \\
\text { nonunion }\end{array}$ & Results & $\begin{array}{l}\text { Time for union } \\
\text { (weeks) }\end{array}$ \\
\hline Schnetzke et al. [22] & Plate + graft & 38.7 & $\begin{array}{l}8.8 \pm 2.4(1) \\
9.0 \pm 3.0(2) \\
\text { (years) }\end{array}$ & 58 & $19 \mathrm{At}, 11 \mathrm{Ht}$ & $\begin{array}{l}\text { 72\% union(1) } \\
93.1 \% \text { union(2) }\end{array}$ & $\begin{array}{l}10.3 \pm 9.5(1) \\
4.7 \pm 3.4(2) \\
\text { (months) }\end{array}$ \\
\hline Huang et al. [23] & LC-DCP & 43.4 (1)and 49.32) & 20.4 & 51 & $51 \mathrm{Ht}$ & $\begin{array}{l}100 \% \text { union } \\
\text { with LC-DCP }\end{array}$ & 9.3(1) and 9.1(2) \\
\hline Slavko et al. [8] & $\begin{array}{l}\text { \|lizarov external } \\
\text { Fixator }\end{array}$ & $38.7 \pm 12.4$ & 45.4 & 12 & $12 \mathrm{At}$ & 100\% union & 10 \\
\hline Kabak et al. [24] & $\begin{array}{l}\text { DCP and LC-DCP, } \\
\text { graft }\end{array}$ & 39.3 and 43.6 & 44.2 & 33 & $25 \mathrm{At}, 8 \mathrm{Ht}$ & $\begin{array}{l}100 \% \text { union } \\
\text { with LC-DCP }\end{array}$ & $\begin{array}{l}9.2(\text { LC-DCP) } \\
11.9(\mathrm{DCP})\end{array}$ \\
\hline Sadiq et al. [26] & DCP, 2-plates & 39 & NA & 20 & NA & 100\% union & 17 \\
\hline Jones et al. [25] & Plate + graft & None & 33 & 14 & $12 \mathrm{At}, 2 \mathrm{Ht}$ & 93\% union & 15.6 \\
\hline Our treatment & 2-Plates + graft & 35 & $45.4 \pm 12.6$ & 12 & $7 \mathrm{Ht}, 5 \mathrm{At}$ & $100 \%$ union & 9 \\
\hline
\end{tabular}

LC-DCP limited contact-dynamic compression plate, DCP dynamic compression plate, $\mathrm{Ht}$ hypertrophic, At atrophic, none not mentioned

(1) Failure of initial surgical treatment (group 1)

(2) Failure of conservative treatment (group 2)

${ }^{(1)}$ Plate revision without bone graft

${ }^{(2)}$ Plate revision with iliac crest bone graft 
Therefore, more patients need to be included in this study to verify the effectiveness of this procedure.

\section{Conclusion}

Our study showed that double-plate with autogenous bone graft may be a prosperous and ideal alternative osteosynthesis technique for treating the atrophic clavicular nonunion, especially those with significant bone gaps. The rigid stability of the double-fixation construct allows the patient to proceed with functional rehabilitation exercise earlier and finally obtain better results. Therefore, double-plate with autogenous bone graft may be a successful salvage procedure when traditional means of achieving union were ineffective.

\section{Acknowledgements}

The authors thank Dr. P. Yin and J. Zhang for their help with the novel ideas in this study.

\section{Authors' contributions}

P. Yin conceived the design of the study and revised the manuscript. J. Zhang, B. Han, and J.M. Zhao performed and collected the data and contributed to the design of the study. J. Zhang and B. Yin worked hard during the revision of the manuscript. The authors read and approved the final content of the manuscript.

\section{Funding}

Not applicable.

\section{Availability of data and materials}

The data used to support the findings of this study are included within the article. All data and materials were in full compliance with the journal's policy.

\section{Ethics approval and consent to participate}

The study was performed in accordance with the ethical standards of the Declaration of Helsinki of 1964. Consent to participate in the study was obtained from all the patients.

\section{Consent for publication}

All patients included in the study provided their informed consent at enrolment and the use of patients' data for research.

\section{Competing interests}

The authors declare that they have no competing interests.

\section{Author details}

'Department of Orthopaedics, The affiliated Hospital of Inner Mongolia Medical University, Hohhot 010010, China. ${ }^{2}$ Department of Orthopaedics, Beijing Chao-Yang Hospital, China Capital Medical University, Beijing 100020, China.

Received: 22 August 2020 Accepted: 9 December 2020

Published online: 07 January 2021

\section{References}

1. O'Neill BJ, Hirpara KM, O'Briain D, McGarr C, Kaar TK. Clavicle fractures: a comparison of five classification systems and their relationship to treatment outcomes. Int Orthop. 2011;35(6):909-14.

2. Naveen BM, Joshi GR, Harikrishnan B. Management of mid-shaft clavicular fractures: comparison between non-operative treatment and plate fixation in 60 patients. Strat Ttrauma Limb Reconstr. 2017;12(1):11-8.

3. Mirzatolooei F. Comparison between operative and nonoperative treatment methods in the management of comminuted fractures of the clavicle. Acta Orthop Traumatol Turc. 2011:45(1):34-40.

4. Olsen BS, Vaesel MT, JO S. Treatment of midshaft clavicular nonunion with plate fixation and autologous bone grafting. J Shoulder Elbow Surg. 1995;4:337-44.
5. Leroux T, Wasserstein D, Henry P, Khoshbin A, Dwyer T, Ogilvie-Harris D, et al. Rate of and risk factors for reoperations after open reduction and internal fixation of midshaft clavicle fractures: a population-based study in Ontario, Canada. J Bone Joint Surg Am. 2014;96(13):1119-25.

6. Boehme $\mathrm{D}$, Curtis $\mathrm{RJ} \mathrm{Jr}$, DeHaan $\mathrm{J}$, et al. The treatment of nonunion of fractures of the mid-shaft of the clavicle with an intramedullary Hagie pin and autogenous bone graft. AAOS Instr Course Lect. 1993:42:283-90.

7. Momberger NG, Smith J, Coleman DA. Vascularized fibular grafts for salvage reconstruction of clavicle nonunion. J Shoulder Elbow Surg. 2000;9(5):389-94.

8. Tomić S, Bumbasirevic M, Lesić A, Bumbasirević V. Modification of the llizarov external fixator for aseptic hypertrophic nonunion of the clavicle: an option for treatment. J Orthop Trauma. 2006;20(2):122-8.

9. Boyer Ml, Axelrod TS. Atrophic nonunion of the clavicle: treatment by compression plate, lag-screw fixation and bone graft. J Bone Joint Surg Br. 1997:79(2):301-3.

10. Niikura T, Lee SY, Sakai Y, Nishida K, Kuroda R, Kurosaka M. Radiationassociated fracture nonunion of the clavicle treated with locking plate fixation and autologous bone grafting. Case Rep Med. 2012;2012:407349.

11. Xu HW, Hu JY, Jia SH, Zhang ZW, Gong SL. AO elastic intramedullary nailing for the treatment of clavicle fractures. Zhongguo Gu Shang. 2015;28(2):106-11.

12. Slette EL, Mikula JD, Turnbull TL, Hackett TR. Treatment of midshaft clavicle fractures: application of local autograft with concurrent plate fixation. Arthrosc Tech. 2016;5(3):e557-62.

13. Xiao H, Gao H, Zheng T, Zhao J, Tian Y. Plate fixation versus intramedullary fixation for midshaft clavicle fractures: meta-analysis of complications and functional outcomes. J Int Med Res. 2016;44(2):201-15.

14. Gao Y, Chen W, Liu YJ, Li X, Wang HL, Chen ZY. Plating versus intramedullary fixation for mid-shaft clavicle fractures: a systemic review and meta-analysis. PeerJ. 2016;4:e1540.

15. Lädermann A, Abrassart S, Denard PJ, Tirefort J, Nowak A, Schwitzguebel AJ. Functional recovery following early mobilization after middle third clavicle osteosynthesis for acute fractures or nonunion: a case-control study. Orthop Traumatol Surg Res. 2017;103(6):885-9.

16. Haverstock BD, Mandracchia VJ. Cigarette smoking and bone healing: implications in foot and ankle surgery. J Foot Ankle Surg. 1998;37(1):69-74 discussion 8.

17. Taylor JC. Delayed union and nonunion of fractures. In: Crenshaw AH, editor. Campbell's operative orthopaedics. 8th ed. St Louis: Mosby; 1992.

18. UM D i, Akgul T, Polat G, Cakmak MF, Dikici F. Autologous segmental tibia bone transfer in the treatment of distal tibia Gustilo-Anderson type-III open fracture: a case report. Int J Surg Case Rep. 2016;27:113-8.

19. McHorney CA, Ware JE Jr, Raczek AE. The MOS 36-Item Short-Form Health Survey (SF-36): II. Psychometric and clinical tests of validity in measuring physical and mental health constructs. Med Care. 1993;31(3):247-63.

20. Katolik LI, Romeo AA, Cole BJ, Verma NN, Hayden JK, Bach BR. Normalization of the Constant score. J Shoulder Elbow Surg. 2005;14(3):279-85.

21. Constant $\mathrm{CR}$, Murley AH. A clinical method of functional assessment of the shoulder. Clin Orthop. 1987;23:160-4.

22. Schnetzke M, Morbitzer C, Aytac S, Erhardt M, Frank C, Muenzberg M, et al. Additional bone graft accelerates healing of clavicle non-unions and improves long-term results after 8.9 years: a retrospective study. J Orthop Surg Res. 2015;10:2.

23. Huang HK, Chiang CC, Hung SH, Su YP, Chiu FY, Liu CL, et al. The role of autologous bone graft in surgical treatment of hypertrophic nonunion of midshaft clavicle fractures. J Chin Med Assoc. 2012;75(5):216-20.

24. Kabak S, Halici MT, et al. Treatment of midclavicular nonunion: comparison of dynamic compression plating and low-contact dynamic compression plating techniques. J Shoulder Elbow Surg. 2004;13:396-403.

25. Jones GL, McCluskey GM 3rd, Curd DT. Nonunion of the fractured clavicle: evaluation, etiology, and treatment. J South Orthop Assoc. 2000;9:43-54.

26. Sadiq S, Waseem M, Peravalli B, Doyle J, Dunningham T, Muddu BN. Single or double plating for nonunion of the clavicle. Acta Orthop Belg. 2001;67(4): 354-60.

27. El Haj M, Khoury A, Mosheiff R, Liebergall M, Weil YA. Orthogonal double plate fixation for long bone fracture nonunion. Acta Chir Orthop Traumatol Cech. 2013;80(2):131-7.

\section{Publisher's Note}

Springer Nature remains neutral with regard to jurisdictional claims in published maps and institutional affiliations. 